\title{
EFEITO DE EXTRATOS ORGÂNICOS, ASSOCIADOS AO SURFACTANTE TWEEN 80, NA GERMINAÇÃO E CRESCIMENTO DE PLÂNTULAS DE ALFACE
}

\author{
Effect of organic extracts associated with surfactant Tween 80 \\ on seed germination and seedling growth of lettuce \\ Cláudio Costa dos Santos ${ }^{1}$, Denilson Ferreira de Oliveira², \\ Luis Wagner Rodrigues Alves ${ }^{3}$, Itamar Ferreira de Souza ${ }^{4}$, Danilo Augusto S. Furtado ${ }^{5}$
}

\begin{abstract}
RESUMO
Com este trabalho, visou-se a identificar, por meio de bioensaio, o efeito dos extratos de caruru (Amaranthus retroflexus L.), capim-marmelada (Brachiaria plantaginea (Link.) Hitchc.), mentrasto (Ageratum conyzoides L.) e de três cultivares de milho (AG1051, C333 e C435) sobre a germinação e crescimento de alface (Lactuca sativa L. cv. Marisa AG216). Os extratos metanólicos foram concentrados sob vácuo e solubilizados em surfactante Tween 80 a 1\% (v/v) em água. A seguir, aplicaram-se as soluções obtidas em papel de filtro sobre placa de Petri, onde foi semeada alface. Utilizaram-se água destilada como testemunha e surfactante Tween 80 a 1\% como tratamento branco. O extrato de mentrasto, o de caruru e da cultivar de milho AG1051 promoveram redução no índice de velocidade de germinação em relação à testemunha com água destilada. O percentual de germinação foi afetado apenas pelo extrato de mentrasto (82,5\% de redução). Todos os extratos e o surfactante Tween 80 provocaram inibição do crescimento de radículas de plântulas de alface, com redução de comprimento de raiz entre 9,53 e 14,83 mm, e de hipocótilo, entre 21,6 a 30,95 mm.
\end{abstract}

Termos para indexação: Alelopatia, planta daninha, milho.

\section{ABSTRACT}

This work aimed at identifying, through bioassay, the effect of organic extracts of pigweed (Amaranthus retroflexus L.), signal grass (Brachiaria plantaginea (Link.) Hitchc.), ageratum (Ageratum conyzoides L.) and three corn cultivars (AG1051, C333 and C435) on lettuce (Lactuca sativa L. cv. Marisa AG216) germination and seedling. Thus, the methanolic extracts of their straws were concentrated under vacuum and dissolved in $1 \%(\mathrm{v} / \mathrm{v})$ aqueous surfactant Tween 80 . Then, the resulting solutions were applied to filter papers contained in Petri dishes, where lettuce was sowed. Distilled water and $1 \%$ Tween 80 were used as controls treatment. The corn cultivar extracts AG1051, pigweed and ageratum promoted reduction of the germination index in relation to the control with distilled water. The germination percentage was affected by ageratum extract $(82.5 \%$ less than the control). All extracts and the surfactant Tween 80 promoted inhibition lettuce seedling growth with reduction of root length between 9.53 and $14.83 \mathrm{~mm}$ and hypocotyls between 21.64 to $30.95 \mathrm{~mm}$.

Index terms: Allelopathy, weeds, corn.

(Recebido para publicação em 14 de março de 2003 e aprovado em 18 de maio de 2003)

\section{INTRODUÇÃO}

As interações alelopáticas entre plantas, que ocorrem mediante a liberação de substâncias pelas partes aéreas, subterrânea ou pela decomposição de material vegetal, podem causar efeitos detrimentais de uma espécie sobre outra (LORENZI, 2000). Para exemplificar, pode-se citar as plantas daninhas caruru-gigante (Amaranthus retroflexus L.) e capim-marmelada
(Brachiaria plantaginea (Link ) Hitchc), que afetam o desenvolvimento de plantas de diversas culturas (ALMEIDA, 1985; WILLIS, 1994). Em espécies do gênero Amaranthus, efeitos inibitórios foram verificados por Connick et al. (1989). As plantas daninhas são afetadas por culturas como o milho (Zea mays L.), por exemplo, o qual, por meio de suas propriedades ale-

1. Engenheiro Agrônomo, MS, Pesquisador EPAMIG - Caixa Postal 176, 37200-000 - Lavras, MG. csantoscosta@ bol.com.br

2. Professor, Dr., Departamento de Química - Universidade Federal de Lavras/UFLA - Caixa Postal 37 - 37200-000 - Lavras, MG.

3. Engenheiro Agrônomo, MS, Prof. UNIFENAS

4. Professor, PhD, Departamento de Agricultura/UFLA

5. Graduando, Departamento de Agricultura/UFLA. 
lopáticas, inibe o crescimento de ançarinha-branca (Chenopodium album L.) e caruru (ALTIERI e DOLL, 1978; BUHLER et al., 1996).

Além das plantas daninhas, espécies cultivadas têm seu desenvolvimento afetado pela interferência alelopática do milho (HAMILTON, 1964; TANG et al., 1975; ZUNIGA et al., 1983; ALMEZORI et al., 1999). Observações de campo apontam indícios do efeito prejudicial dessa cultura sobre mudas de cafeeiro transplantadas em sucessão ao milho (ABRAHÃO, 2000) (Edinaldo José Abrahão - EMATER - Lavras, MG. Fevereiro, 2000 - comunicação pessoal).

Substâncias, como os surfactantes, utilizadas como adjuvantes de herbicidas ou para preparação de substratos apresentam efeito inibitório sobre o crescimento das plantas (GUIMARÃES, 1995; STAHLMAN et al., 1999). Schopmeyer (1961) observou redução no crescimento de plântulas de Pinus taeda L. quando aplicou surfactante Tween 20 nas folhas em concentração de $0,05 \%$. Swanson e Whitney (1953) constataram redução na absorção de fósforo por feijoeiro (Phaseolus vulgaris L. cv. Black Valemntine) após a pulverização foliar com surfactante Tween 80. Souza (2001) (Itamar Ferreira de Souza - Dep. de Agricultura - Universidade Federal de Lavras - Lavras - MG. Abril - comunicação pessoal) afirmou que o surfactante Tween 20 causou efeito negativo sobre o crescimento de plantas em solução nutritiva adicionada de sorgoleone.

Cientes da grande importância das interações alelopáticas entre plantas, neste trabalho procurou-se averiguar, por meio de teste in vitro, os efeitos na germinação de sementes e crescimento de plântulas de alface (Lactuca sativa L.), provocados pela produção de substâncias fitotóxicas oriundas do milho e plantas daninhas.

\section{MATERIAL E MÉTODOS}

O bioensaio foi conduzido no Departamento de Agricultura da Universidade Federal de Lavras, em delineamento inteiramente casualisado, com 4 repetições, no mês de abril de 2001. Os tratamentos foram constituídos por extratos a 5\% [massa de palha (g)/volume de solução aquosa do surfactante Tween $80(\mathrm{~mL})$ ] de capim-marmelada, caruru, mentrasto e de três cultivares de milho (C333, C435 e AG1051), uma testemunha com água destilada e um branco com surfactante Tween 80 a $1 \%(\mathrm{v} / \mathrm{v})$.

Os extratos foram preparados com as partes aéreas das plantas daninhas e das cultivares de milho (obtidas de um experimento de campo implantado com os mesmos objetivos), todas coletadas durante o estádio de floração, as quais foram secas em estufa com circulação forçada de ar a $45^{\circ} \mathrm{C}$, até atingirem peso constante e moídas em fragmentos de $0,5 \mathrm{~mm}$. Tomaram-se, de cada espécie ou cultivar, $20 \mathrm{~g}$ dessa palha para serem imersos em metanol por 36 horas. Após esse período, filtraram-se os extratos através de algodão. Concentraram-se os extratos obtidos sob vácuo até secura. Os resíduos resultantes foram dissolvidos em $400 \mathrm{~mL}$ de solução de surfactante Tween 80 a $1 \%(\mathrm{v} / \mathrm{v})$ para serem submetidos aos testes in vitro.

O bioensaio foi conduzido em placas de Petri autoclavadas, contendo papel de filtro umedecido com $2 \mathrm{~mL}$ do extrato, e semeadas com dez sementes de alface cv. Marisa AG216, mantidas sob balcão do laboratório à temperatura ambiente (aproximadamente $25^{\circ} \mathrm{C}$ ), por 10 dias. Foi adicionada água destilada às placas de Petri, quando necessário, para manter a umidade para germinação e crescimento das plântulas.

A germinação foi avaliada em intervalos de dois dias. Foram calculados os índices de velocidade de germinação (IVG) e percentual de germinação, utilizando-se como critério a protusão de radícula. As raízes e o hipocótilo foram medidos aos 10 dias após a semeadura com auxílio de uma régua graduada em milímetros. $\mathrm{O}$ IVG foi calculado pela equação descrita por Maguire (1962): $\mathrm{IVG}=\mathrm{G} 1 / \mathrm{N} 1+\mathrm{G} 2 / \mathrm{N} 2+\ldots+\mathrm{G}_{\mathrm{n}} / \mathrm{N}_{\mathrm{n}}$; em que $\mathrm{G} 1$, $\mathrm{G} 2, \mathrm{G}_{\mathrm{n}}$ representam o número de sementes normais germinadas até o enésimo dia; $\mathrm{N} 1, \mathrm{~N} 2, \mathrm{~N}_{\mathrm{n}}$ representam o número de dias em que se avaliou a germinação $G_{1}$, $\mathrm{G}_{2}, \mathrm{G}_{\mathrm{n}}$.

Para análise de variabilidade dos dados, aplicou-se análise de variância, e as médias foram comparadas pelo teste Tukey a $5 \%$ de probabilidade.

\section{RESULTADOS E DISCUSSÃO}

Com os dados obtidos, conforme Tabela 1, foi observado que o índice de velocidade de germinação da alface foi afetado negativamente pelo extrato da cultivar de milho AG1051 e pelas espécies caruru e mentrasto, com IVG de 3,68; 3,68; e 0,29, respectivamente, quando o IVG da testemunha com água destilada foi de 5,48 . O uso do surfactante Tween 80 não afetou essa característica. $\mathrm{O}$ percentual de sementes germinadas foi afetado negativamente apenas pelo extrato de mentrasto (7,5\% de sementes germinadas). O extrato de caruru apresentou tendência de redução do percentual de germinação, porém, sem diferir significativamente da testemunha com água destilada $(70 \%$ e $90 \%$, respectivamente). 
Para comprimento de radícula, o surfactante Tween 80 mostrou efeito inibitório, com 63,8\% de inibição em relação à testemunha com água destilada, sem diferir significativamente dos extratos das cultivares milho C333 e C435. Os extratos da cultivar AG1051 e das espécies daninhas caruru e marmelada causaram redução de $82 \%, 91 \%$ e $89 \%$, respectivamente, quando comparados com a testemunha com água destilada. Maior inibição (99\%) foi causada pelo extrato de mentrasto.

Para crescimento do hipocótilo, o surfactante Tween 80 ocasionou 76,3\% de inibição em relação à testemunha com água destilada. As espécies daninhas caruru e marmelada mostraram-se significativamente iguais ao surfactante, enquanto os extratos orgânicos de milho apresentaram uma tendência de inibir os efeitos do surfactante Tween 80 . O extrato de mentrasto mostrou uma forte inibição dessa característica.

Considerando que houve efeito negativo do surfactante Tween 80, o qual estava presente nos demais tratamentos como solvente, pode-se inferir que os efeitos inibitórios de todos extratos sobre o comprimento de radícula e dos extratos das espécies daninhas sobre o crescimento do hipocótilo tenham sido acrescidos pelo surfactante. Sugere-se, pois, a realização de novos testes sem esse produto, a fim de se verificar o verdadeiro potencial alelopático de cada planta daninha e cultivar de milho, sem a interferência do surfactante Tween 80 .

TABELA 1 - Efeito de extratos aquosos a 5\% de plantas daninhas e cultivares de milho no IVG (índice de velocidade de germinação), no percentual de germinação e no crescimento de radícula e hipocótilo de alface.

\begin{tabular}{|c|c|c|c|c|}
\hline \multirow{2}{*}{ Tratamentos } & \multirow{2}{*}{ IVG } & \multirow{2}{*}{ \% Germinação } & \multicolumn{2}{|c|}{ Comprimento (mm) } \\
\hline & & & Radícula & Hipocótilo \\
\hline Testemunha & $5,48 \mathrm{a}$ & $90 \mathrm{a}$ & $14,93 \mathrm{a}$ & $31,45 \mathrm{a}$ \\
\hline Tween 80 & $5,5 \mathrm{a}$ & 90 a & $5,4 \mathrm{~b}$ & $7,41 \mathrm{bc}$ \\
\hline C333 & $3,98 \mathrm{ab}$ & $90 \mathrm{a}$ & $3,1 \mathrm{bc}$ & $9,81 \mathrm{~b}$ \\
\hline $\mathrm{C} 435$ & $4,22 \mathrm{ab}$ & $90 \mathrm{a}$ & $3,15 \mathrm{bc}$ & $9,53 \mathrm{~b}$ \\
\hline AG1051 & $3,68 \mathrm{~b}$ & $82,5 \mathrm{a}$ & $2,7 \mathrm{c}$ & $9,75 \mathrm{~b}$ \\
\hline Caruru & $3,68 \mathrm{~b}$ & $70 \mathrm{a}$ & $1,33 \mathrm{~cd}$ & $4,96 \mathrm{c}$ \\
\hline Mentrasto & $0,29 \mathrm{c}$ & $7,5 \mathrm{~b}$ & $0,1 \mathrm{~d}$ & $0,5 \mathrm{~d}$ \\
\hline Marmelada & $4,7 \mathrm{ab}$ & $85 \mathrm{a}$ & $1,6 \mathrm{~cd}$ & $6,26 \mathrm{c}$ \\
\hline $\mathrm{CV}(\%)$ & 16,91 & 15,39 & 24,49 & 11,02 \\
\hline
\end{tabular}

Médias seguidas pela mesma letra dentro da mesma coluna são significativamente iguais pelo teste Tukey a $\mathbf{5 \%}$ de significância. 


\section{CONCLUSÕES}

a) $\mathrm{O}$ índice de velocidade de germinação foi afetado pelo extrato da cultivar de milho AG1051 e das plantas daninhas caruru e mentrasto.

b) $O$ percentual de germinação foi afetado negativamente apenas pelo extrato de mentrasto.

c) Os extratos das cultivares de milho e das plantas daninhas, associados ao surfactante Tween 80 e esse isoladamente, provocaram inibição do crescimento da radícula e do hipocótilo das plântulas de alface.

d) O surfactante Tween 80 afetou o crescimento de radícula e hipocótilo das plântulas de alface.

\section{REFERÊNCIAS BIBLIOGRÁFICAS}

ALMEIDA, F. S. Plantio direto: efeitos alelopáticos das coberturas mortas. Informe Agropecuário, Belo Horizonte, v. 11, n. 129, p. 44-51, set. 1985.

ALMEZORI, H. A.; AL-SAADAWI, I. S.; ALHADITHI, R. T. Allelopathic effects of corn residues on the subsequent corn crop. Allelopathy Journal, Hisar, v. 6, n. 2, p. 193-200, 1999.

ALTIERI, M. A.; DOLL, J. D. The potential of allelopathy as a tool for weed management in crop fields. PANS, London, v. 24, n. 4, p. 495-502, Dec. 1978.

BUHLER, D. D.; MESTER, T. C.; KOHELER, K. A. The effect of maize residues and tillage on emergence of Setaria faberi, Abutilon theophrasti, Amaranthus retroflexus and Chenopodium album. Weed Research, Oxford, v. 36, n. 2, p. 153-165, 1996.

CONNICK, W. J.; BRADOW, J. M.; LEGENDRE, M. G. Identification and bioactivity of volatile allelochemicals from Amaranthus residues. Agricultural And Food Chemistry, Washington, v. 37, p. 792-796, 1989.

GUIMARÃES, M. C. Crescimento de crisântemo em substrato contendo surfactantes. 1995. $77 \mathrm{f}$. Dissertação (Mestrado) - Universidade Federal de Viçosa, Viçosa, 1995.
HAMILTON, R. H. Tolerance of serveral grass species to 2-chloro-s-triazine herbicides to degradation and content of benzoxazolinone derivatives. Agricultural and Food Chemistry, Washington, v. 12, n. 1, p. 1417, 1964.

LORENZI, H. Manual de identificação de identificação e controle de plantas daninhas: plantio direto e convencional. Nova Odessa: Instituto Plantarum, 2000 .

MAGUIRE, J. D. Speed of germination-aid in selection evaluation for seedling emergence and vigour. Crop Science, Madison, v. 2, p. 176-177, 1962.

SCHOPMEYER, C. S. Absorption and translocation of foliarly applied phophorus by loblolly pine seedlings. Plant Physiology, Maryland, v. 36, 1961. Supplement 33.

SWANSON, C. A.; WHITNEY, J. B. Studies on the translocation of foliar applied $\mathrm{P}^{32}$ and other radioisotopes in bean plant. American Journal of Botany, Columbus, v. 40, p. 816-823, 1953.

STAHLMAN, P. W.; CURRIE, R. S.; EL-HAMID, M. A. Nitrogen carrier and suefactant increase foliar injury in winter wheat (Triticum aestivun). Weed Technology, Champaign, v. 11, n. 1, p. 7-12, Jan./Mar. 1999.

TANG, C.; CHANG, S. N.; HOO, D. Gas chromatographic determination of 2(3)-benzoxazolinones from cereal plants. Phytochemistry, Oxford, v. 14, p. 2077-2079, 1975.

WILLIS, R. J. Terminology and trends in allelopathy. Allelopathy Journal, Hisar, v. 1, n. 1, p. 6-28, 1994.

ZUNIGA, G. E.; ARGANDONA, V. H.; NIEMEYER, H. M.; CORCUERA, L. J. Hydroxamic acid content in wild and cultivated gramineae. Phytochemistry, Oxford, v. 22, n. 12, p. 2665-2668, 1983. 